\title{
Artigos
}

\section{"Vinte mil pedras no caminho": a representação gráfica de uma carreira de usuário de drogas baseada em sua autobiografia}

"Twenty thousand stones along the way": a graphic representation of a drug user career based on his autobiography (abstract: p. 18)

"Veinte mil piedras en el camino": la representación gráfica de una carrera de usuario de drogas basada en su autobiografía (resumen: p. 18)

Ygor Diego Delgado Alves ${ }^{(a)}$

<antropologiaygor@yahoo.com.br>

Pedro Paulo Gomes Pereira(b)

$<$ pedropaulopereira@hotmail.com> (a) Programa de Pós-Graduação em Saúde Coletiva (PósDoutorado), Universidade Federal de São Paulo (Unifesp). Rua Botucatu, 740 , sala $404,4^{\circ}$ andar, Vila Clementino. São Paulo, SP, Brasil, 04023-062.

(b) Programa de Pós-Graduação em Saúde Coletiva, Universidade Federal de São Paulo (Unifesp). São Paulo, SP Brasil.

O objetivo deste artigo é, com base em uma narrativa autobiográfica que descreve a carreira de usuário de drogas, construir um diagrama que permita visualizar o desenvolvimento da carreira e dividi-la em fases sucessivas quanto ao incremento ou à diminuição do autocontrole sobre o uso de drogas. A construção de um diagrama nos permitiu visualizar os períodos de maior e menor autocontrole sobre o consumo de substâncias e os principais fatores intervenientes. Tal procedimento mostrou-se uma ferramenta capaz de fornecer uma representação sintética e, ao mesmo tempo, diacrônica da carreira de usuário, dividida em fases sucessivas quanto ao incremento ou à diminuição do autocontrole, que constatamos depender da droga consumida e do contexto pessoal e social do usuário.

Palavras-chave: Carreira do usuário. Crack. Autobiografia. Diagrama. Autocontrole. 


\section{Introdução}

Neste artigo vamos analisar a autobiografia de Fabian Nacer $^{1}$ que consumiu drogas de modo intenso por, ao menos, duas décadas, até completar 36 anos de idade. Por meio dessa narrativa e baseados em autores que se dedicaram a estudar o consumo de drogas sob a perspectiva do uso autocontrolado ${ }^{2-4}$, construiremos um diagrama traçando a carreira de Fabian como usuário de drogas. O termo e o conceito de carreira foram trazidos por Becker $^{2}$ da literatura de administração de empresas, particularmente da administração de recursos humanos. $\mathrm{O}$ termo era usado para se referir à carreira dos funcionários em uma empresa ou no Estado através do tempo. De modo similar, na carreira do usuário, as experiências com o uso de uma ou várias substâncias são dadas de modo diacrônico e não apenas pontualmente. A representação gráfica da carreira do usuário de drogas permitirá visualizar, em um único diagrama, os períodos de maior e menor autocontrole sobre o consumo de substâncias e os principais fatores intervenientes. Trata-se de uma nova ferramenta de análise de casos de pessoas que usam drogas, por meio de uma representação sintética e ao mesmo tempo diacrônica.

Estudos sobre consumo de drogas que observam carreiras de usuários o fazem por motivos variados. Tammi ${ }^{5}$ se preocupou com o tempo necessário para que usuários de drogas se tornassem politicamente conscientes e ativos na Finlândia. As descobertas de $S$ mith ${ }^{6}$ apontaram para os múltiplos papéis e relacionamentos que as mulheres tentam administrar enquanto seguem uma carreira de usuárias de drogas injetáveis (UDI). Ao descrever comportamentos e preferências de uso de drogas, bem como o contexto social e ambiental de jovens e antigos usuários de drogas injetáveis da cidade de Toronto, Firestone e Fischer ${ }^{7}$ concluíram que a janela de oportunidade, para a prevenção da transmissão de doenças e a redução do risco, se apresenta no início da carreira de um UDI. Significa que os esforços de prevenção e as mensagens de redução de danos devem ser direcionados a essa população mais jovem. Silvestre e Manita ${ }^{8}$ relacionaram precarização do vínculo laboral com a carreira de uso de drogas, sendo os momentos de falta de trabalho os mais propensos ao consumo de substâncias. Em um estudo desenvolvido em dois períodos, entre os anos de 1994 e 2006, por Fernandez e MacRae ${ }^{9}$, temos o exemplo mais bem-acabado de estudo de carreiras de usuários. Diferentes padróes de uso da cocaína puderam ser percebidos, juntamente com os sistemas de autorregulação adotados pelos sujeitos e sua retroalimentação, como proposto originalmente por Grund ${ }^{3}$, levando em conta reflexôes de Becker ${ }^{2}$ e Zinberg ${ }^{4}$. Fernandez e MacRae ${ }^{9}$ (p. 48) concluíram que as carreiras malsucedidas de usuários que consumiram drogas de modo inseguro foram marcadas pelo fracasso em escapar dos processos de rotulação, sofrendo maior exclusão e piores condiçôes de vida e sobrevivência.

O objetivo deste artigo é, por meio da análise da carreira de usuário de drogas, tal como narrada por Fabian Nacer em sua autobiografia ${ }^{1}$, construir um diagrama que permita visualizar o desenvolvimento da carreira e dividi-la em fases sucessivas quanto ao incremento ou à diminuição do autocontrole sobre o uso de drogas. Ao diagrama junta-se a representação dos fatores que intervieram positiva ou negativamente sobre o autocontrole, a disponibilidade da droga, os rituais e regras, e a estrutura de vida, com suas diferentes grandezas e a importância de cada fase. O que faremos tem o intuito 
de verificar se o conjunto assim produzido é capaz de nos auxiliar a perceber quanto a evolução do autocontrole sobre o uso de drogas, no decorrer de uma carreira, pode ser ou não multidirecional, ou seja, nem sempre no sentido da sua perda.

\section{A autobiografia}

Estudos sobre carreiras de usuários de drogas que se utilizam de biografias estão presentes desde Zinberg ${ }^{4}$ e MacRae e Simóes ${ }^{10}$. A escrita dos fatos particulares que impactaram o consumo de drogas de uma pessoa, durante as várias fases da sua vida, costuma basear-se no estudo biográfico e na narração oral colhida pelo pesquisador. Quanto à narração sobre a vida de Fabian Nacer, escrita sob a forma de um livro autobiográfico ${ }^{1}$, temos um texto cujo fio condutor é seu consumo de drogas. A obra nos revelou uma descrição ampla, pormenorizada e abrangente de todo o período percorrido na carreira de usuário do autor e, por isso, nos deu a possibilidade de identificar fases distintas quanto ao autocontrole do uso e aos fatores preponderantes na sua variação.

Fabian Nacer, oriundo da classe média paulistana do bairro de Moema, também residiu nos bairros do Campo Belo, Aeroporto e Brooklin. Segundo as áreas de ponderação do Censo de 2000, essas são regiôes habitadas "prioritariamente pelos grupos sociais mais ricos"11 (p. 15). Filho de pais empresários, testemunhou a separação precoce do casal e passou a viver com a mãe, que o abandonaria poucos anos depois. Sofreu assédio sexual por parte da avó materna e revelou desconforto com a situação familiar do início da adolescência: "Meu pai casou de novo e eu não me encaixava. Minha mãe casou e eu não me encaixava” (p. 26).

Aos 14 anos de idade consumiu bebidas alcoólicas, cigarros, ansiolíticos, antidepressivos, chá de lírio e de cogumelos, além do anticolinérgico Artane. Aos 17 anos iniciou o uso de maconha, abandonando as outras substâncias com exceção dos cigarros e bebidas alcoólicas; aos 18 anos de idade utilizou bebidas alcoólicas em qualquer evento ou interação social que exigisse alguma desinibição: "Já não conseguia nem ir pra uma festa ou chegar numa garota sem álcool na ideia” (p. 68). Idade em que também iniciou a fabricação do próprio inalante ou lança-perfume. Aos 19 anos, tornou-se fornecedor de maconha para pequenos traficantes da escola, pouco antes de ter a primeira experiência no consumo de cocaína que também se pôs a revender.

Viajou aos Estados Unidos da América (EUA) para cursar aeronáutica e permaneceu consumindo álcool e cocaína. Sofreu acidente aéreo ao pilotar aeronave sob efeito de drogas e retornou ao Brasil. De volta aos EUA trabalhou em empregos de baixa qualificação e consumiu maconha, álcool, cocaína e LSD. No Brasil abriu um bar que faliu em seis meses. Iniciou o consumo diário de cocaína. Como observou Faupel ${ }^{12}$, são as rupturas na estrutura mais convencional de vida, como a perda de um emprego ou a separação familiar, que têm consequências mais profundas na natureza e na extensão do consumo de drogas.

Mais uma vez nos EUA, consumiu cocaína, vindo a mendigar e experimentar heroína. Ao retornar ao Brasil reencontrou a mãe depois de 13 anos de separação. Mudou-se para Florianópolis e, por cerca de dois anos, consumiu apenas maconha e álcool até voltar a 
cheirar cocaína. Sofreu um golpe por parte da polícia, foi preso e teve de retornar a São Paulo, onde intensificou o uso de cocaína cheirada de modo solitário e em pequenos hotéis da região central da cidade. Após breve período na cidade de Natal, retornou, aos 28 anos de idade, a viver com a mãe no bairro de Moema.

Ao regressar uma última vez aos EUA experimentou crack, consumindo compulsivamente, em um padrão tipo binge e de modo solitário: "Minha vida virou ficar trancado no quarto me drogando" (p. 169). Novamente no Brasil, volta a residir com a mãe de quem subtrai pequenas somas de dinheiro e alguns bens a fim de sustentar o consumo de crack na rua. Começou a estabelecer uma vida cotidiana baseada na permanência nas imediaçốes dos pontos de comércio e consumo da droga. Por conta de seu novo padrão de uso, foi encaminhado a um psicólogo e um psiquiatra, sendo medicado. Também se consultou com religiosos. Foi internado pela primeira vez por dois dias. Ao retornar, encontrou negadas as possibilidades de abrigo em residências do círculo familiar, o que o obrigou a nova internação. Não se adaptou ao modelo religioso-espiritual ${ }^{13}$ de internação ${ }^{1}$ (p. 178-80). Mudou de comunidade terapêutica, leu a bíblia cristã, único livro disponível, e se converteu ao mesmo tempo em que apresentava delírios de tipo religioso ${ }^{14}$ : “[...] estava vendo anjos. [...] todos sentadinhos na cerca do campo, em torno da chácara” ${ }^{1}$ (p. 190). Ao término da internação, retornou à residência materna, frequentando cultos religiosos.

Iniciou novo trabalho e voltou a consumir crack no padrão binge, na companhia de travestis, em hotéis da região central de São Paulo. Foi surpreendido pela mãe que, acompanhada da polícia, o perseguiu em um conhecido local de comércio de drogas do bairro do Brooklin. Realizou um último grande furto à própria residência e, após acidente automobilístico, chegou à Praça da República, região central, onde tentou sobreviver como pedinte até residir algum tempo com uma travesti. Conheceu os melhores pontos de venda de crack da região, mas teve dificuldade em conseguir fundos para aquisição da droga. Descobriu e assumiu para si o que chama de "padrão de vida" dos usuários de crack do centro da cidade: "[...] em torno da pedra, de conseguir a pedra, de fumar a pedra, de curtir a noia da pedra [...]. Para se cobrir, um papelão bastava” (p. 213).

Os perigos e a violência da Cracolândia fizeram que Fabian tivesse desejos de retornar ao convívio familiar. A consciência da oposição da família ao seu retorno, que seria possível apenas se realizasse novo tratamento, fez que desistisse. A ideia de ter provocado sentimentos de raiva na família contribuiu para adiar um novo contato. No primeiro ano na Cracolândia, dormia na rua e possuía poucos fundos para aquisição de crack. Acabou por fumar apenas duas pedras de crack por dia, quando seu ideal seria de dez. Viveu em condiçốes precárias, próximas ao padrão do junkie de rua ${ }^{12}$, com baixa disponibilidade da droga e também baixa estrutura de vida (conjunto de relações e atividades que moldam o cotidiano). Foi alvo de diversas abordagens por parte do poder público e de igrejas que não surtiram efeito. Motivado pelas dificuldades em permanecer na região, com a qual nunca se identificou, procurou a família e se internou em uma clínica, onde conheceu os 12 passos de Narcóticos Anônimos. Saiu após um mês de internação e retornou à Cracolândia. 
Percebeu que a mendicância rendia mais nos bairros de classe média, como Chácara Santo Antônio e Brooklin. Passou a pedir dinheiro na região. Na primeira tentativa conseguiu dinheiro suficiente para adquirir 15 pedras de crack na "[...] boca da Água Espraiada, onde se podia comprar pedra da boa com o dobro do tamanho das que eu comprava na Cracolândia [...]"1 (p. 229), local onde, outrora, Fabian costumava pegar maconha e cocaína.

Com a nova fonte prolífica de renda e a facilidade de fornecimento de crack, atingiu um padrão de consumo estável. Mesmo usando uma grande quantidade de droga, viveu um cotidiano que considerava satisfatório ${ }^{1}$ (p. 230). Pôde planejar suas atividades diárias para obtenção de fundos e consumo de crack (circunscrito ao ambiente seguro de quartos de hotel e em horários definidos). "Assim que juntava 100 reais, me enfiava num hotelzinho de dez reais do Largo Treze, na Cupecê ou nos arredores do Jockey, no meio do dia, lá pelas onze da manhã, passava umas três, quatro horas fumando e vendo filme pornô - e ainda tomava um banho"1 (p. 230).

Foi levado a trajar apenas roupas limpas com as quais conseguia obter maior sucesso ao pedir dinheiro nas residências de classe média. Andava asseado e de barba feita. Com o dinheiro arrecadado podia, também, adquirir maconha para moderar alguns dos efeitos negativos do crack. "Foram seis meses de paraíso" 1(p.230), em um padrão próximo ao estabelecido por Faupel ${ }^{12}$ como de junkie estabilizado: com grande disponibilidade da droga e estrutura de vida. Até que uma importante mudança no contexto social viesse a desestabilizar a rotina favorável: a "[...] Água Espraiada, em menos de um ano, foi inflando de tanto drogado que começou a circular por ali por causa das muitas bocas que proliferaram na região [...]"1 (p. 230).

A maior disponibilidade de crack no território, algo positivo para os consumidores, acabou por atrair grande quantidade de usuários, mas trouxe uma consequência prática deletéria para a obtenção de fundos para aquisição de drogas: “[...] todo mundo pedindo dinheiro nos mesmos lugares, pras mesmas pessoas, nos mesmos faróis” ( $\mathrm{p}$. 230). A nova cena de uso

[...] concorria com a Cracolândia do Ceasa pelo posto de segunda maior da cidade. Ambas nasceram das vezes em que tentaram dispersar a da Luz, como se fosse aquela coisa de esparramar o formigueiro, sacou? ${ }^{1}$. (p.230)

O fato nos dá uma pequena dimensão das consequências das ações do poder público, na chamada "guerra às drogas" 15 , sobre a distribuição espacial dos locais de comércio e consumo de substâncias. Uma maior repressão na Cracolândia, região central da cidade, provocou a dispersão dos consumidores de crack pelos bairros que antes desconheciam grandes cenas de uso de drogas ${ }^{16}$. Possivelmente, foi também um dos motivos do aumento do número de pontos de venda. O poder público, agindo de modo repressivo, acabou por fomentar a demanda por crack em novos lugares, gerando novas possibilidades de negócios para o tráfico. 
Fabian voltou ao estado de junkie de rua ${ }^{12}$; precisou gastar muito tempo na luta por obtenção de fundos para a aquisição de crack. Seu cotidiano deixou de ser preenchido pelo tempo vivido no interior dos quartos de hotel e passou a ser composto por uma sucessão extensa de horas despendidas em um comportamento ritualizado de pedir dinheiro. A antiga satisfação proporcionada por um suprimento regular de crack foi substituída pela fissura.

A vida estava ficando difícil. Ficava na fissura $90 \%$ do tempo, porque eu não conseguia tanta grana como no começo. Tinha de ficar pedindo três horas para conseguir algum e comprar pedra ${ }^{1}$. (p. 233)

Mesmo dedicando a maior parte de seu tempo à obtenção de fundos, não conseguia dormir nos hotéis onde costumara ficar e teve que viver na rua. A vida nas ruas, como apontaram Alves et a $l^{17}$, é muito deletéria em comparação à permanência em hotéis. Assim, o aspecto físico e de vestimenta de Fabian se deteriorou, o que dificultou, ainda mais, conseguir dinheiro. Os moradores dos bairros de classe média se recusavam a ajudar o consumidor de crack a manter seu hábito, acreditando, talvez, que quanto mais difícil fosse conseguir a droga menos droga seria usada e, quem sabe, alguma melhoria ocorresse na vida do usuário. Porém, o efeito foi inverso: "Estava mais magro, mais sujo, claramente um drogado de rua... Quem ia me dar dinheiro pra droga?"” (p. 233).

Ter de consumir crack na rua é sujeitar-se a riscos ambientais sérios, o maior deles é o de ter a droga e o cachimbo levado e mesmo de ser espancado pela polícia, como aconteceu com Fabian. Sensações paranoicas são compreensíveis no novo ambiente:

[...] entrava na viagem paranoica em algum canto enfiado [...]. Minha receita financeira e eu emagrecemos juntos, em proporção inversa à paranoia, que só crescia $^{1}$. (p. 233)

A vida na rua impõe uma nova cotidianidade por conta da difícil situação quanto às oportunidades para se obter dinheiro:

[...] tinha polícia chegando com tudo em cima, a rotina de andar sem tomar banho por meses, de começar a me deixar levar, de fazer minhas necessidades na rua, onde desse vontade $[\ldots]^{1}$. (p. 233)

Não apenas a vida na rua, mas o ambiente, o bairro, o estigma desqualificante em torno do usuário de crack, do zumbi ${ }^{16}$, impelem a pessoa para uma situação marcada pela abjeção ${ }^{18}$ e, como em um círculo vicioso, a degradação se retroalimenta. "Se fede? O que você acha? E você acha que eu estava ligando? E quem ia deixar eu

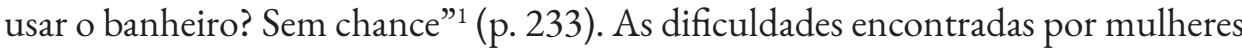
frequentadoras da Cracolândia em manter a higiene foram relatadas em Alves ${ }^{16}$.

A ausência de um apropriado cuidado de si aparece como corolário da sua impossibilidade prática em ambiente hostil, marcado pela repulsa, em que a grande dificuldade está em "[...] descolar onde fumar sem ficar noiado com os fantasmas..." (p. 
234). Um padrão de uso de crack renovado pela fissura no ambiente da rua: "Batia uma irritação absurda... Ficava agressivo - o que era péssimo para os negócios...” (p. 234). Sem outra possibilidade de alívio a não ser pelo consumo matinal da droga, Fabian ficou sujeito à ditadura do "corre"16. Nessa busca incessante por fundos de aquisição, postava-se no farol e começava a pedir dinheiro e a consumir 15 pedras diárias, números idênticos aos encontrados por Alves ${ }^{16}$ entre usuários de crack de São Paulo.

Fabian, ao viver no "corre” (p. 239), empreendia seu próprio ajustamento para máximo rendimento dos movimentos e gestos por meio de atividades codificadas em táticas ${ }^{19}$. Trata-se da busca pela melhor relação possível entre paranoia, fissura, obtenção de fundos, aquisição da droga e uso do crack. Como declarou o próprio autor, "ia administrando" esses fatores, mesmo com todos os impedimentos estabelecidos pela situação de vulnerabilidade imposta pela rua ${ }^{20}$. A Figura 1 procura ilustrar a relação entre o ambiente social e as transformaçôes físicas e psíquicas por meio de uma engrenagem biopsicossocial.

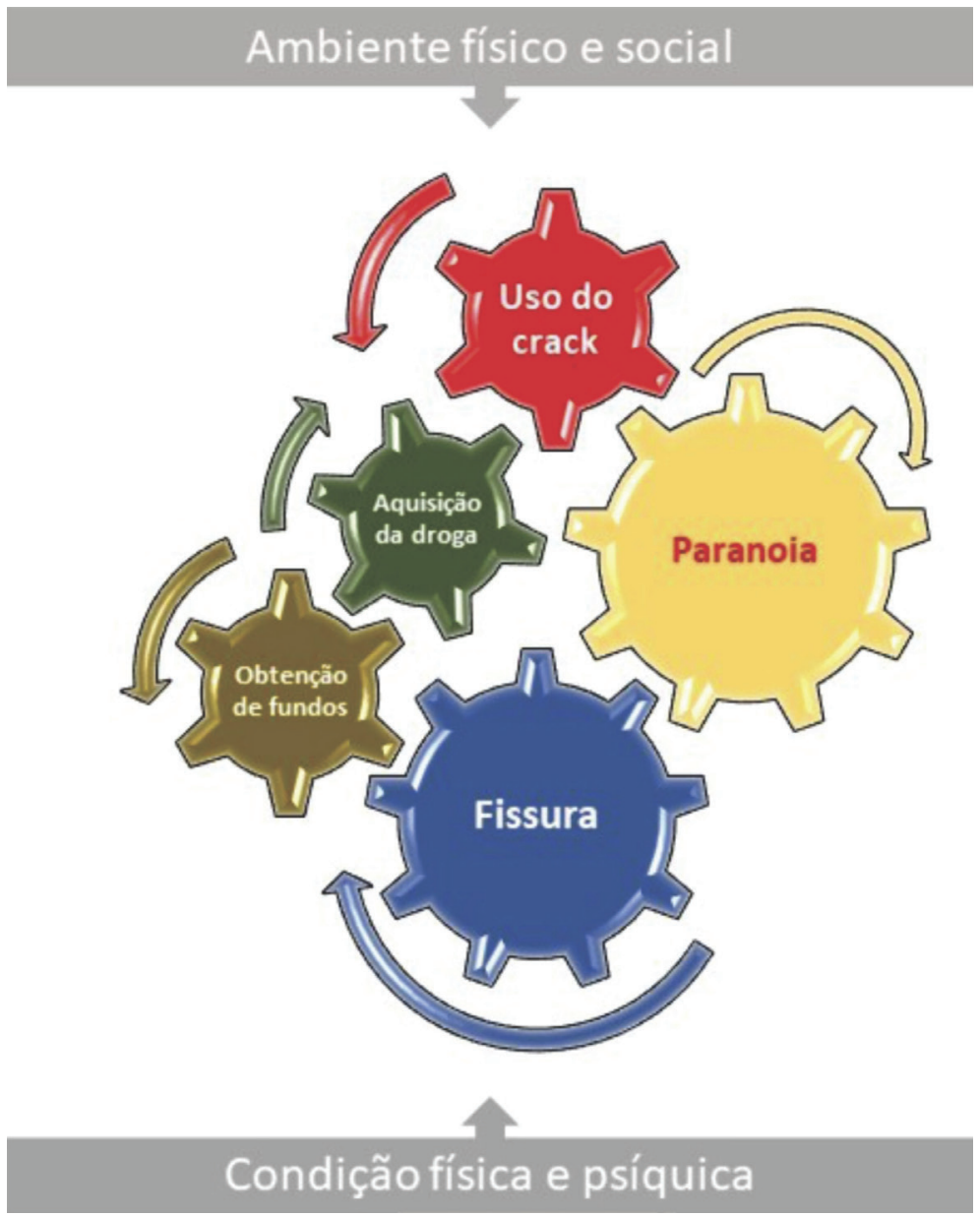

Figura 1. Engrenagem biopsicossocial 
As dificuldades em obter dinheiro e a lembrança do dia em que sua mãe, acompanhada pela polícia, o surpreendera no ponto de comércio de drogas acabaram por se transformar em uma sucessão de pensamentos obsessivos:

Comecei a acreditar com todas as minhas forças que havia uma conspiração, pessoas que ficavam no farol anterior avisando pra não me darem dinheiro. Um grupo de pessoas contratadas pela minha família $[\ldots]^{1}$. (p. 244)

Fabian nomeou essas pessoas imaginárias como "exército branco" que passaram a ser responsáveis pelos infortúnios decorrentes da situação de junkie de rua.

O fato de a oleosidade acumulada na pele, após meses sem tomar banho, umedecer e estragar a pedra de crack trouxe a necessidade de banhar-se e fez que, entre outros motivos, Fabian retornasse à residência materna algumas vezes. Situação em que era convidado a se internar. Foram 25 internaçóes, muitas delas motivadas pelo desejo de se afastar da rua. O que não significa que não fossem períodos de abstinência, o problema maior parecia estar no chamado modelo religioso-espiritual ${ }^{13}$ :

[...] passei três semanas por lá, orando, orando e orando, engordei um pouco, perdi o aspecto de drogado, arrumei minhas roupas e acalmou minhas noias. [...] Não entendia, mesmo, como estar ali, no meio de tanta reza, poderia produzir algum milagre $[\ldots]^{1}$. (p. 268)

Somada aos períodos de internação houve uma busca contínua por sair do ambiente da rua, seja frequentando casas de crack, imóveis transformados por usuários da droga em locais degradados de consumo, seja adentrando imóveis desocupados ou indo a residências de novas amizades feitas em torno do uso da droga. Havia também uma busca constante pelo convívio com outros consumidores da substância. Algo verificado em Alves e Gomes Pereira ${ }^{21}$ como importante para os usuários de crack, mas sempre estava presente uma questão de classe. Na predileção por quem "[...] era de família, como eu, com condiçóes de vida, de dar a volta por cima, que não era sem eira nem beira" (p. 291); e a fim de evitar o que Fabian denominou como sendo a "escória do crack": pessoas de origem "pobre e de famílias desestruturadas"1 (p. 293).

Alves ${ }^{16}$ mostrou como ao corpo fatigado, sedento e faminto do usuário de crack na rua corresponde uma mente propícia a sonhar acordada e despertar, para depois sonhar outras vezes até desligar. Portanto, o estado comparável ao do zumbi, que não resume a integralidade da vida do consumidor de crack nas ruas, diz respeito ao movimento do corpo extenuado durante o sonho provocado após dias e dias de uso em estado alerta. Fabian nos revela em sua autobiografia a imensa dificuldade em dormir e a necessidade, imposta pela vida na rua, de prosseguir consumindo crack. "Do jeito que eu andava, só dormia quando a exaustão me derrubava - e isso era raro. Mais comum era passar a noite aceso. Imagina ficar sem crack numa situação dessas”' (p. 275).

À mente alerta, corresponde um corpo em movimento; ao corpo fatigado, corresponde uma mente que sonha acordada e que, por vezes, pode estar mais desperta ou mais absorta em um sonho. A percepção embaralhada tem na realidade, o sonho, e no sonho, 
a realidade. Ao cair em um sono profundo, deitado em uma calçada ou mal acomodado em sua maloca, Fabian estaria em condiçôes de descansar um pouco mais; porém, para isso, pagou o preço de ir desfalecendo em um longo processo de luta por permanecer um pouco mais semiacordado à custa do consumo de pedras de crack. Assim sendo, o que se chama de binge, uso de drogas até o completo esgotamento, pode ser mais bem-conceituado ao se levar em conta o usuário, seu corpo/mente em um ambiente que proporcione pedras de crack. Pedras essas obtidas pelo movimento do "corre" e necessárias para manter um corpo/mente alerta até o embaralhamento de sonho com realidade, como observou Fabian sobre seu quinto ano como consumidor da droga nas ruas: "Não havia espaço no meu dia ou na minha mente pra nada que não fosse ligado ao crack. Realidade e viagem era quase a mesma coisa"1 (p. 305).

Se o uso de drogas, em geral, nos permite ter uma nova percepção da realidade, o uso do crack permite mesclá-la com nossos sonhos em um ambiente onde tudo parece conspirar para dificultar o descanso. Nos últimos dois anos na rua, a vida cotidiana se tornou ainda mais difícil. No intuito de livrar-se da sensação persecutória advinda da ideia recorrente de que um "exército branco" viria sequestrá-lo, o intervalo entre uma "paulada” (termo referente ao ato de fumar crack) e outra teve de diminuir drasticamente.

[...] a noia batia cada vez mais rápido, me fazendo ver coisas, imaginar coisas. [...] E nem aguentava mais trinta minutos, o tempo de conseguir a grana no farol, trocar as moedas e ir conseguir o crack na boca ${ }^{1}$. (p. 310)

As dificuldades aumentaram ainda mais devido a sua aparência e ao fato de ter-se tornado conhecido. Fabian não conseguia dinheiro com a mesma facilidade. Creditou o fato ao "exército branco" e começou a se esconder no esgoto, próximo ao córrego Águas Espraiadas. Lembremos que existem bases factuais para a paranoia: diversas prisões, violência física grave desferida pela Polícia Militar e perseguição pela família nos locais de comércio de crack. "Meus delírios persecutórios não me deixavam em paz um minuto sequer. Viver tinha virado um inferno, com ou sem droga" (p. 327). Em meio a todas essas dificuldades, planejou, durante as últimas dez internações, o que faria caso parasse de fumar crack. Então, após alguns períodos entre internaçóes sucessivas consumindo apenas álcool ou maconha, foi sedado por um ano, fez terapia e não voltou mais a consumir drogas. O que encerra nossa descrição da carreira de usuário de Fabian Nacer e nos permite traçar sua representação gráfica.

\section{A representação da carreira de usuário}

Ao colocarmos em um plano cartesiano os acontecimentos mais marcantes da carreira de usuário de drogas de Fabian Nacer, em uma representação gráfica "matematizável”22 (p. 316), pudemos vislumbrar sua evolução no decorrer dos anos em relação com o maior ou o menor autocontrole sobre o consumo de substâncias (Figura 2). Tal procedimento nos levou a obter uma linha que marca altos e baixos, o que demonstra certa irregularidade no desenvolvimento de sua relação com as drogas e, posteriormente, de forma mais acentuada, com o crack. Para efeitos de melhor exposição gráfica, a linha do tempo foi dividida em duas partes. A primeira representa o início do consumo de drogas, 
(e)

ainda na adolescência, até quase trinta anos de idade. A segunda imagem representa a evolução do consumo do crack até o abandono do uso da droga (Figura 3). Os eventos e fatos mais marcantes que levam ao aumento ou diminuição do autocontrole sobre o consumo de drogas estão descritos em caixas de texto associadas a cada período.

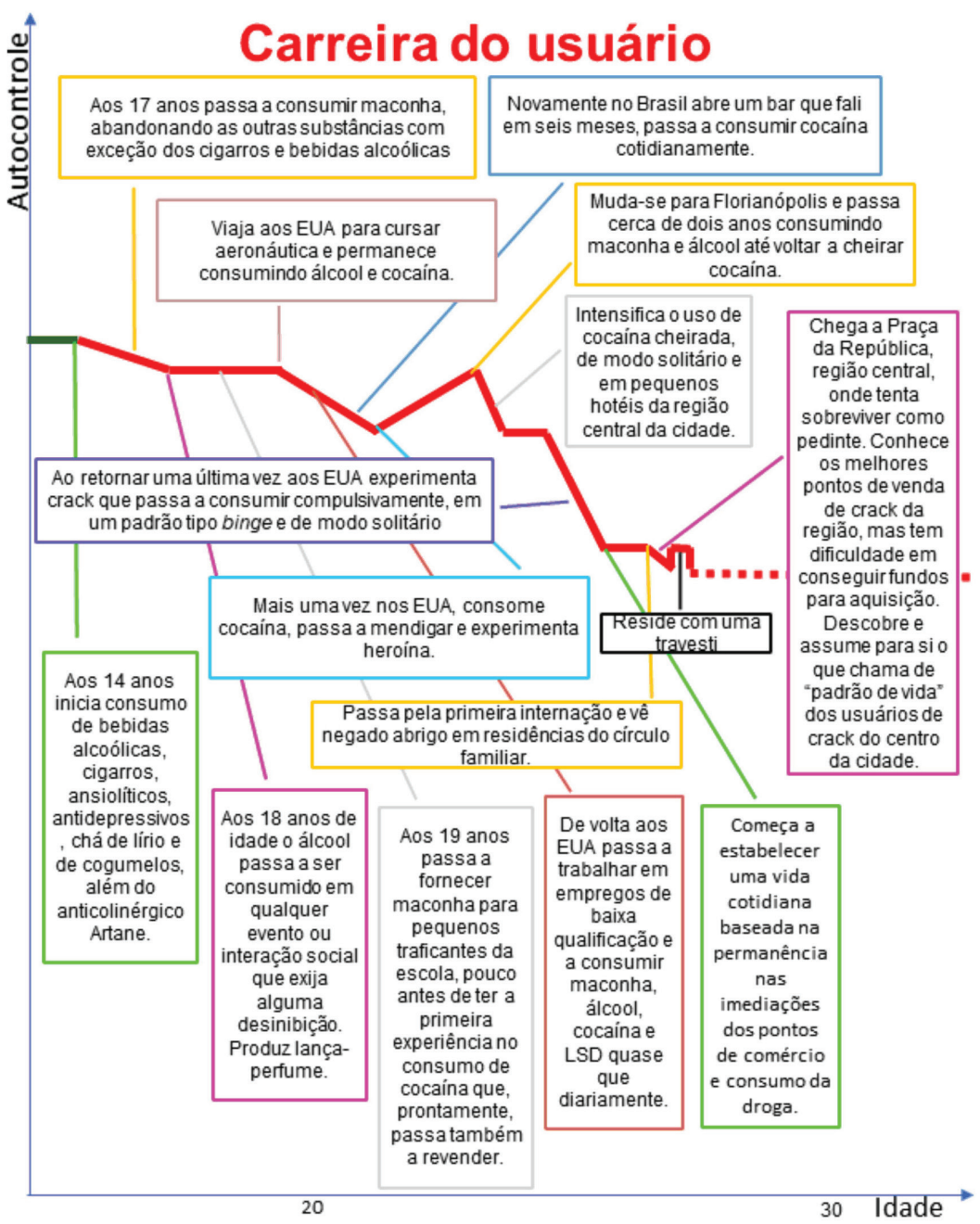

Figura 2. A linha vermelha representa a carreira de uso de drogas de Fabian Nacer no decorrer dos anos, quanto ao maior ou ao menor autocontrole. 
(e)

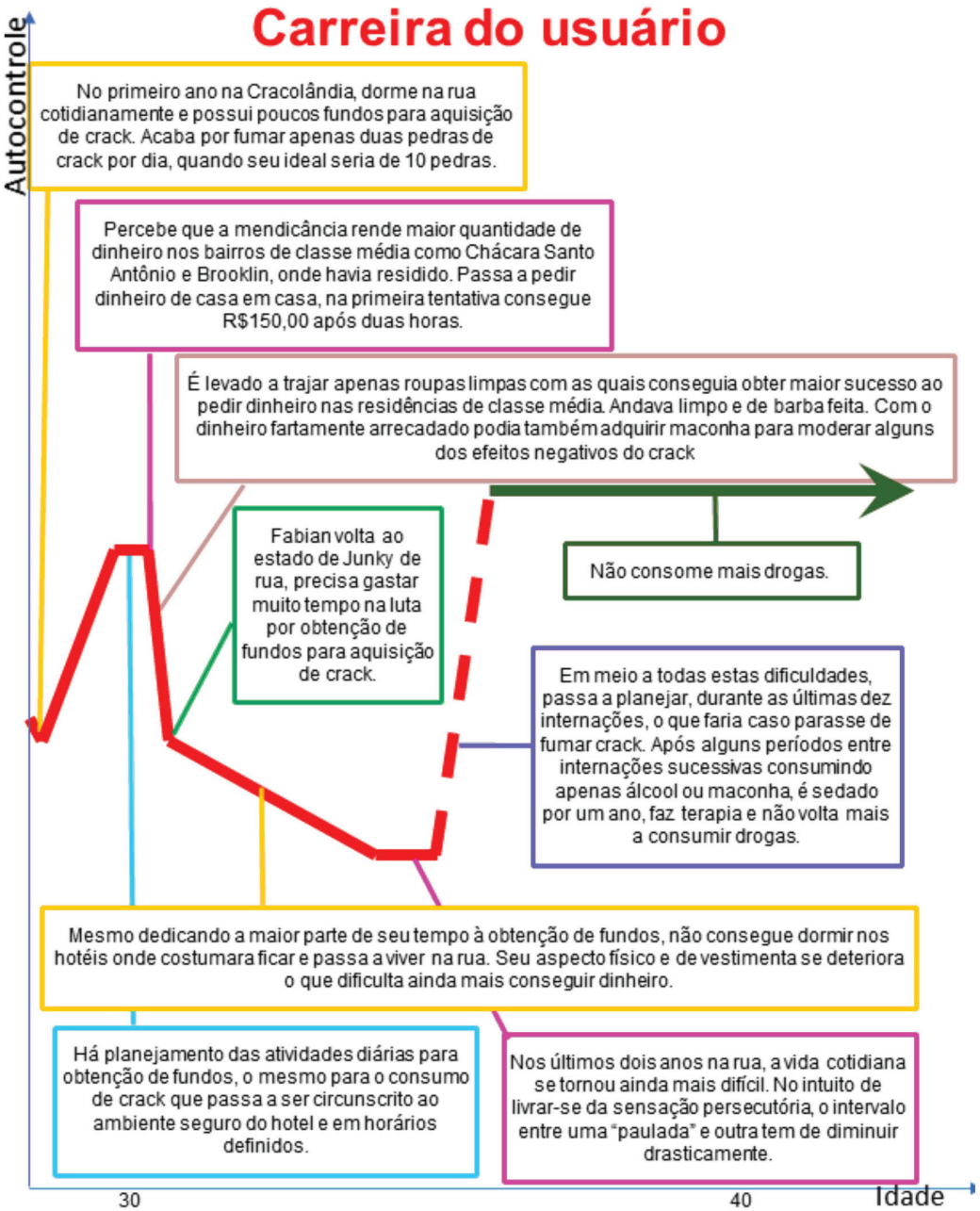

Figura 3. A linha vermelha representa a carreira de uso de drogas de Fabian Nacer no decorrer dos anos, quanto ao maior ou ao menor autocontrole. 
As duas figuras procuram mostrar o processo de construção da carreira de usuário de drogas de Fabian Nacer. As caixas de texto aparecem em cores distintas para facilitar a visualização e a separação entre umas e outras, ligadas à linha vermelha que traça a carreira e contém os fatos mais relevantes nas mudanças quanto ao autocontrole do consumo de substâncias. O eixo das abscissas representa o passar da idade, enquanto o das ordenadas, o autocontrole. A inclinação das retas que traçam a carreira é determinada pela variação na intensidade da sucessão dos eventos. Assim, uma reta é mais inclinada para baixo quanto mais os acontecimentos narrados forem deletérios ao autocontrole. As retas que apontam para cima traçam sua melhora.

A terceira imagem representa a carreira de usuário de drogas de Fabian Nacer sob efeito da tríade disponibilidade da droga, rituais e regras, e estrutura de vida (DDRREV), como presente em Grund ${ }^{3}$. A disponibilidade da droga (DD) depende de mecanismos de mercado definidos pelo tráfico, muitas vezes em resposta a políticas governamentais como o aumento da repressão. Os rituais e regras $(\mathrm{R} R$ ) em torno do consumo de drogas podem ser apreendidos pela socialização centrada no grupo de pares, assim como serem mais centrados na aquisição de fundos ou na segurança e no conforto do usuário, a depender de outros determinantes externos, como a disponibilidade da droga e a estrutura de vida $(\mathrm{EV})$. Essa última característica do contexto social em que se consome drogas diz respeito a atividades, conexôes, compromissos e obrigaçôes da pessoa e está profundamente ligada a fatores culturais, como o maior ou o menor estigma em torno da droga e do usuário.

Todas as vezes em que esses aspectos se apresentam representados acima da linha vermelha, que traça a carreira de usuário de drogas de Nacer, é porque exerceram influência no sentido de diminuir seu autocontrole sobre o consumo de substâncias. De modo inverso, ao serem representadas abaixo da linha vermelha é por exercerem influência positiva sobre o autocontrole. Os três elementos da tríade DDRREV são apresentados, também, em sua maior ou menor influência sobre o desenvolvimento da carreira de usuário em determinado período, podendo ser representados por figuras maiores ou menores. Os períodos de 1 a 6 foram estabelecidos em função de suas características mais marcadamente ascendentes ou descendentes no autocontrole do consumo de drogas (Figura 4). 
(e)

\section{Carreira do usuário}

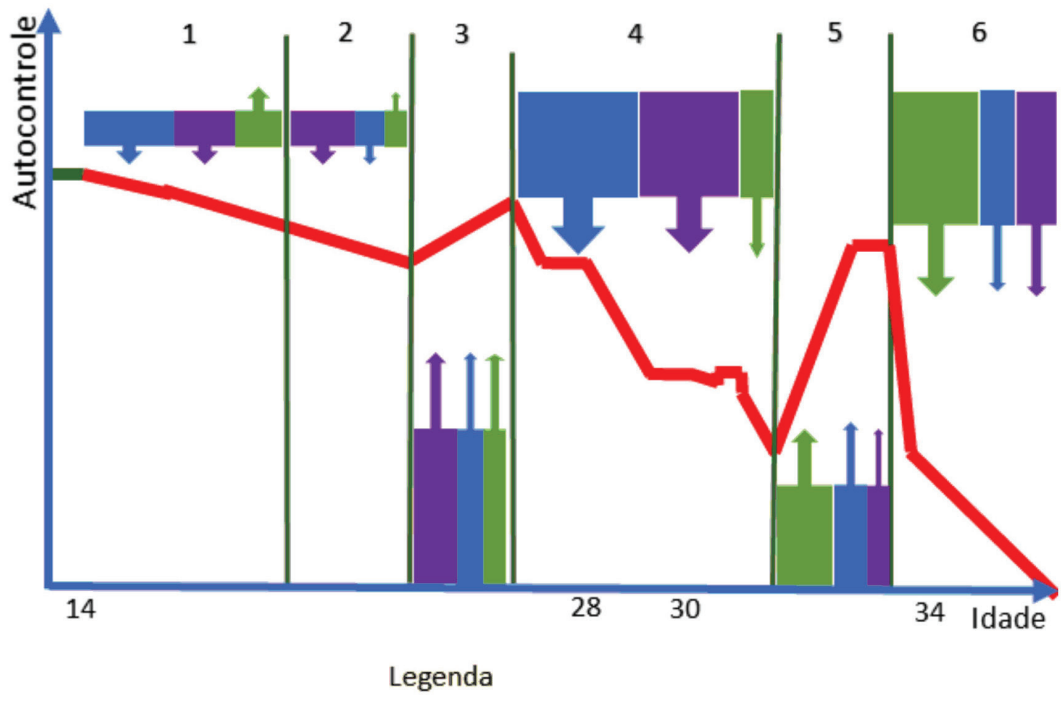

Disponibilidade da droga

Rituais e regras

Aumento

Estrutura de vida

Diminuição

Figura 4. A linha vermelha representa a carreira de uso de drogas de Fabian Nacer sob efeito da tríade DDRREV. 
O período inicial do consumo de drogas, número 1, é marcado pela múltipla experimentação de substâncias em ambiente compartilhado por adolescentes, no qual se destaca a pouca presença de rituais e regras destinadas a controlar o uso. A falta de pessoas mais experientes nos locais em que as drogas são consumidas, os meios familiar e escolar conturbados e a grande densidade social de jovens em busca de sensaçóes proporcionadas pelas substâncias dificultam o autocontrole. A grande disponibilidade de drogas viabilizada pelo pequeno tráfico também contribui no mesmo sentido deletério.

O número 2 marca uma forte deterioração do autocontrole sobre o consumo de substâncias, impulsionada, em grande parte, pela viagem aos EUA e pelo fracasso no curso de aeronáutica. Fracasso esse que provocou um breve retorno ao Brasil, seguido por nova volta aos EUA, mas dessa vez em condiçôes muito precárias: sem um objetivo claro que passou a ser preenchido pelo consumo intensivo e variado de drogas. Não há moradia nem atividades profissionais fixas e, tampouco, a companhia de pessoas que não consumam drogas. A grande disponibilidade de substâncias acabou também por contribuir para uma diminuição do autocontrole.

A mudança para a cidade de Florianópolis marcou um período, de número 3, de grande aumento do autocontrole sobre o uso de drogas. A falta de dinheiro não impediu que Nacer estabelecesse uma rotina diária em que trabalhou e consumiu maconha acompanhada de quantidades moderadas de álcool. A conquista de um emprego e de mais dinheiro alterou a rotina que passou a ser marcada por viagens e maior disponibilidade de drogas. Mas apenas o golpe sofrido pela polícia local, que se apossou dos bens de Fabian e o obrigou a sair da cidade, foi capaz de desencadear nova baixa do autocontrole.

Ao retornar de Florianópolis à cidade de São Paulo iniciou-se nova fase, a de número 4 , de constante e acentuada perda de autocontrole sobre o consumo de drogas. $\mathrm{O}$ consumo de cocaína cheirada, que havia se iniciado na capital catarinense, assumiu novo ritual no interior de hotéis. $\mathrm{O}$ mesmo consumo solitário e em padrão binge ocorreu em novo retorno aos EUA, só que com crack. De volta ao Brasil, a degradação da estrutura de vida, provocada pela permanência cotidiana nos pontos de comércio e consumo de crack, fez que a família, vítima de seus furtos, condicionasse continuar abrigando Fabian Nacer a caso ele se submetesse à internação. O que, em vez de melhorar seu autocontrole, fez que se instalasse na Cracolândia, onde passou a viver como usuário de crack nas ruas. A pouca disponibilidade de drogas piorou ainda mais sua situação, forçando-o a um cotidiano marcado por rituais destinados à aquisição de fundos. Há apenas um curto período de melhora quando residiu com uma travesti.

Uma nova e importante reviravolta ocorreu quando uma mudança de local, da Cracolândia para bairros da zona sul, aumentou o acesso a fundos de aquisição e a disponibilidade de drogas. O quinto período da linha, que representa a carreira de uso, é marcado pela melhoria nos rituais e regras, com uma rotina de poucas horas dedicadas a pedir dinheiro e a usar crack em hotéis com a possibilidade de comprar maconha para se livrar de parte dos efeitos negativos. O ritual de consumir drogas nos hotéis permitiu que Nacer andasse com roupas novas e pudesse tomar banho.

O sexto e último período da carreira de uso de Fabian Nacer foi determinado pela radical diminuição dos fundos para aquisição de crack e da sua disponibilidade. Isso o levou a um cotidiano imerso no ambiente físico marcado pelas acomodações terríveis 
nos bueiros, pelos invernos gélidos e veróes causticantes, acrescidos ao contexto social violento, proporcionado pelas prisóes e surras provocadas pela polícia, e hostil em relação a pessoas que pedem dinheiro naqueles bairros de classe média da zona sul de São Paulo. Sob tais injunções, as condiçôes físicas de Fabian se deterioraram, marcadas pela magreza e pela sujeira, enquanto a paranoia e a fissura caracterizaram seu estado psíquico nos últimos meses que permaneceu nas ruas. Uma vida cadenciada pelo ritual de pedir dinheiro por horas a fio até poder comprar crack para, em seguida, fumar nas ruas em sucessivas tentativas vãs de livrar-se da paranoia e da fissura.

\section{Notas finais}

No decorrer da pesquisa vimos como os eventos de inadaptação em ambas as residências parentais, o malogro no propósito de se formar piloto nos EUA, a falência de um negócio, um acidente automobilístico, uma demissão e os roubos de seus bens por parte da polícia, foram capazes de provocar grandes sentimentos de fracasso, assim como os períodos de falta de trabalho ${ }^{8}$, tornando Fabian, sucessivamente, mais propenso ao consumo de substâncias.

Após essas rupturas na estrutura mais convencional de vida ${ }^{12}$ e depois de muitas ocasióes em que furtou bens e dinheiro de familiares, Fabian, como apontado por Fernandez e MacRae ${ }^{9}$ sobre o processo de rotulação do usuário de drogas, foi afastado do ambiente doméstico e teve de viver nas ruas sob constante violência repressiva policial.

A permanência nas ruas não foi sempre a mesma e Fabian continuamente procurou por melhores condições para obter fundos e usar crack. Por isso, deixou os perigos da Cracolândia e se dirigiu aos bairros de classe média em que havia passado a infância e a adolescência, e onde a atividade de pedir dinheiro era mais rentável. Com a nova fonte prolífica de renda e facilidade no fornecimento de crack, atingiu um padrão de consumo estável, circunscrito ao ambiente seguro do hotel e em horários definidos. Mesmo usando uma grande quantidade de droga, viveu um cotidiano que, anos depois, viria recordar-se como tendo sido muito satisfatório.

A ação repressiva do poder público na Cracolândia acabou por fomentar a demanda por crack em novos lugares, como os recém-frequentados por Fabian, gerando novas possibilidades de negócios para o tráfico, mais repressão e aumento do número de pedintes, o que causou maior dificuldade na obtenção de fundos, levando Fabian novamente ao estado de junkie de rua ${ }^{12}$. Seu cotidiano deixou de ser preenchido pelo tempo vivido no interior dos quartos de hotel e passou a ser composto por uma sucessão extensa de horas despendidas em um comportamento ritualizado de pedir dinheiro. A antiga satisfação, proporcionada por um suprimento regular de crack, foi substituída pela fissura.

Essa carreira de usuário, após ser representada em um diagrama, se revelou depender de fatores associados em torno da tríade DDRREV, oscilante entre períodos de maior incremento ou diminuição do autocontrole de Fabian Nacer sobre seu consumo de drogas. Mesmo com uma tendência geral negativa, foi possível visualizar, a cada período, os elementos de maior influência. Por vezes, uma melhora na estrutura de vida ou na disponibilidade de drogas pôde influenciar positivamente a carreira de Fabian. A disponibilidade de drogas revelou-se o único fator cujo aumento pôde contribuir tanto positiva quanto negativamente para o autocontrole. 
O desenvolvimento da carreira de usuário de drogas de Fabian Nacer, conforme narrada em sua autobiografia, corrobora as ideias de Grund $^{3}$ e Zinberg ${ }^{4}$ quanto à influência do contexto social sobre o autocontrole do consumo de drogas. A construção de um diagrama nos permitiu visualizar os períodos de maior e menor autocontrole sobre o consumo de substâncias e os principais fatores intervenientes. Essa ferramenta se mostrou capaz de fornecer uma representação sintética e, ao mesmo tempo, diacrônica da carreira de usuário, dividida em fases sucessivas quanto ao incremento ou à diminuição do autocontrole sobre o uso de drogas; além da representação dos fatores que intervieram, positiva ou negativamente, sobre esse autocontrole, suas diferentes grandezas e a importância de cada fase.

\section{Contribuições dos autores}

Ambos os autores participaram ativamente de todas as etapas de elaboração do manuscrito.

\section{Financiamento}

Este artigo é fruto de Projeto financiado pelo CNPq, com Bolsa CNPq pós-doutorado [150261/2019-5].

\section{Conflito de interesse}

Os autores não têm conflito de interesse a declarar.

\section{Direitos autorais}

Este artigo está licenciado sob a Licença Internacional Creative Commons 4.0, tipo BY (https://creativecommons.org/licenses/by/4.0/deed.pt_BR).

\section{(cc) BY}

\section{Editora}

Rosana Teresa Onocko Campos

Editora associada

Cristina Larrea Killinger

\section{Submetido em}

17/12/19

Aprovado em

20/10/20 


\section{Referências}

1. Nacer FP. Vinte mil pedras no caminho: a história de um piloto de avião que se tornou morador da Cracolândia. São Paulo: Geração Editorial; 2015.

2. Becker HS. Outsiders: estudos de sociologia do desvio. Rio de Janeiro: Zahar; 2008.

3. Grund JP. Drug use as a social ritual: functionality, symbolism and determinants of self-regulation. Rotterdam: Institute Voor Verslavingsondersoek, Erasmus Universiteit; 1993.

4. Zinberg NE. Drug, set, and setting: the basis for controlled intoxicant use. New Haven: Yale University; 1984.

5. Tammi $T$. Who is the expert. Patient groups and finnish substitution treatment policy. In: Asmussen V, Anker TJ, Tops D, Kouvonen P, editors. Drug users and space for legimitate action. Helsinki: NAD Publication; 2006. p. 23-35.

6. Smith C. Injecting drug use and the performance of rural femininity: an ethnographic study of female injecting drug users in rural North Wales. Crit Criminol. 2014; 22(4):511-25.

7. Firestone M, Fischer B. A qualitative exploration of prescription opioid injection among street-based drug users in Toronto: behaviours, preferences and drug availability. Harm Reduct J. 2008; 5(1):30.

8. Silvestre A, Manita C. Relação drogas-trabalho na construção de carreiras desviantes. Toxicodependencias. 2008; 14(2):3-14.

9. Fernandez O, MacRae E. Entre carreiras, redes e Circuitos: uma abordagem etnográfica dos estilos e padrões de uso de cocaína em São Paulo, 1994 a 2006. In: Fernandez O, Andrade M, Nery-Filho A, organizadores. Drogas e políticas públicas: educação, saúde coletiva e direitos humanos. Salvador, Brasília: Edufba, Abramd; 2015. p. 25-50.

10. MacRae E, Simóes JA. Rodas de fumo: o uso da maconha entre camadas médias urbanas. Salvador: Edufba; 2000.

11. Marques E, Torres H, Bichir R. Espaço e grupos sociais na virada do século XXI. São Paulo, 2000: segregação, pobreza urbana e desigualdade social. São Paulo: Cebrap; 2004. Mimeografado.

12. Faupel C. Shooting dope: career patterns of hard-core heroin users. Florida: University of Florida Press; 1991.

13. Ribeiro FML, Minayo MCS. As comunidades terapêuticas religiosas na recuperação de dependentes de drogas: o caso de Manguinhos, RJ, Brasil. Interface (Botucatu). 2015; 19(54):515-26.

14. Dalgalarrondo P. Religiáo, psicopatologia e saúde mental. Porto Alegre: Artmed; 2009.

15. Karam ML. Violência, militarização e 'guerra às drogas'. In: Kucinski B, Dunker CIL, Pereira CI, Mena F, Mingardi G, Wyllys J, et al. Bala perdida: a violência policial no Brasil e os desafios para sua superação. São Paulo: Boitempo; 2015. p.33-8.

16. Alves YDD. Jamais fomos zumbis: contexto social e craqueiros na cidade de São Paulo. Salvador: EDUFBA; 2017.

17. Alves YDD, Gomes Pereira PP, Peres PS. Nascimento, vida e morte de uma política pública: uma etnografia do programa de braços abertos. Cad Saude Publica. 2020; 36(3): 00213918.

18. Rui T. Nas tramas do crack: etnografia da abjeção. São Paulo: Terceiro Nome; 2014. 
19. Foucault M. Vigiar a punir: história da violência nas prisóes. Petrópolis: Vozes; 1997.

20. Silva CC, Cruz MM, Vargas EP. Práticas de cuidado e população em situação de rua: o caso do consultório na rua. Saude Debate. 2015; 39 Spe:246-56.

21. Alves YDD, Gomes Pereira PP. Uma antropologia do "fluxo": reflexóes sobre dependência no contexto do crack. Interthesis (Florianópolis). 2019; 16(1):121-42.

22. Roque T. História da matemática: uma visão crítica, desfazendo mitos e lendas. Rio de Janeiro: Zahar; 2012.

The objective of this article is to construct a diagram based on the autobiographical narrative that describes the trajectory of a drug user, to allow visualizing the development of his career and dividing it into successive phases regarding the increase or decrease of self-control over drug use. The construction of a diagram allowed us to visualize the periods of increased and decreased self-control over substance use and the main factors involved. This procedure proved to be an able tool to provide a synthetic and, at the same time, diachronic representation of the user's career, divided into successive phases regarding the increase or decrease of self-control, which we found to be dependent on the drug consumed and the personal and social context of the user.

Keywords: Drug user's career. Crack. Autobiography. Diagram. Self-control.

El objetivo de este artículo es, a partir de una narrativa autobiográfica que describe la carrera de usuario de drogas, construir un diagrama que permita visualizar el desarrollo de la carrera y dividirla en fases sucesivas en lo que se refiere al aumento o disminución del autocontrol sobre el uso de drogas. La construcción de un diagrama nos permitió visualizar los períodos de mayor y menor autocontrol sobre el consumo de substancias y los principales factores intervinientes. Tal procedimiento se mostró una herramienta capaz de suministrar una representación sintética y, al mismo tiempo, diacrónica de la carrera de usuario, dividida en fases sucesivas con relación al aumento o la disminución del autocontrol, que conforme constatamos depende de la droga consumida y del contexto personal y social del usuario.

Palabras clave: Carrera del usuario. Crack. Autobiografía. Diagrama. Autocontrol. 